\title{
Importance of fibrinolytic changes in liver surgery
}

A.Ozolina, V.Biltauere, A.Ozolins, I.Vanags

Orto Clinic, Riga, Latvia

Riga Stradins University, Riga, Latvia

Pauls Stradins Clinical University hospital, Riga, Latvia

Introduction Bleeding is a frequent complication of liver surgery. Unbalance between tissue plasminogen activator (t-PA) and plasminogen activator inhibitor-1 (PAI-1) concentrations might increase bleeding. Our aim was to analyze perioperative fibrinolytic changes during liver surgery.

\section{Materials and Methods}

We evaluated 15 patients for inclusion into a prospective pilot study of liver surgery. We assessed fibrinolysis by plasma PAI-1 and t-PA::

- before surgery (T1)

- before Pringle maneuver (T2)

- at the end of surgery (T3)

- 24 hours postoperatively (T4)

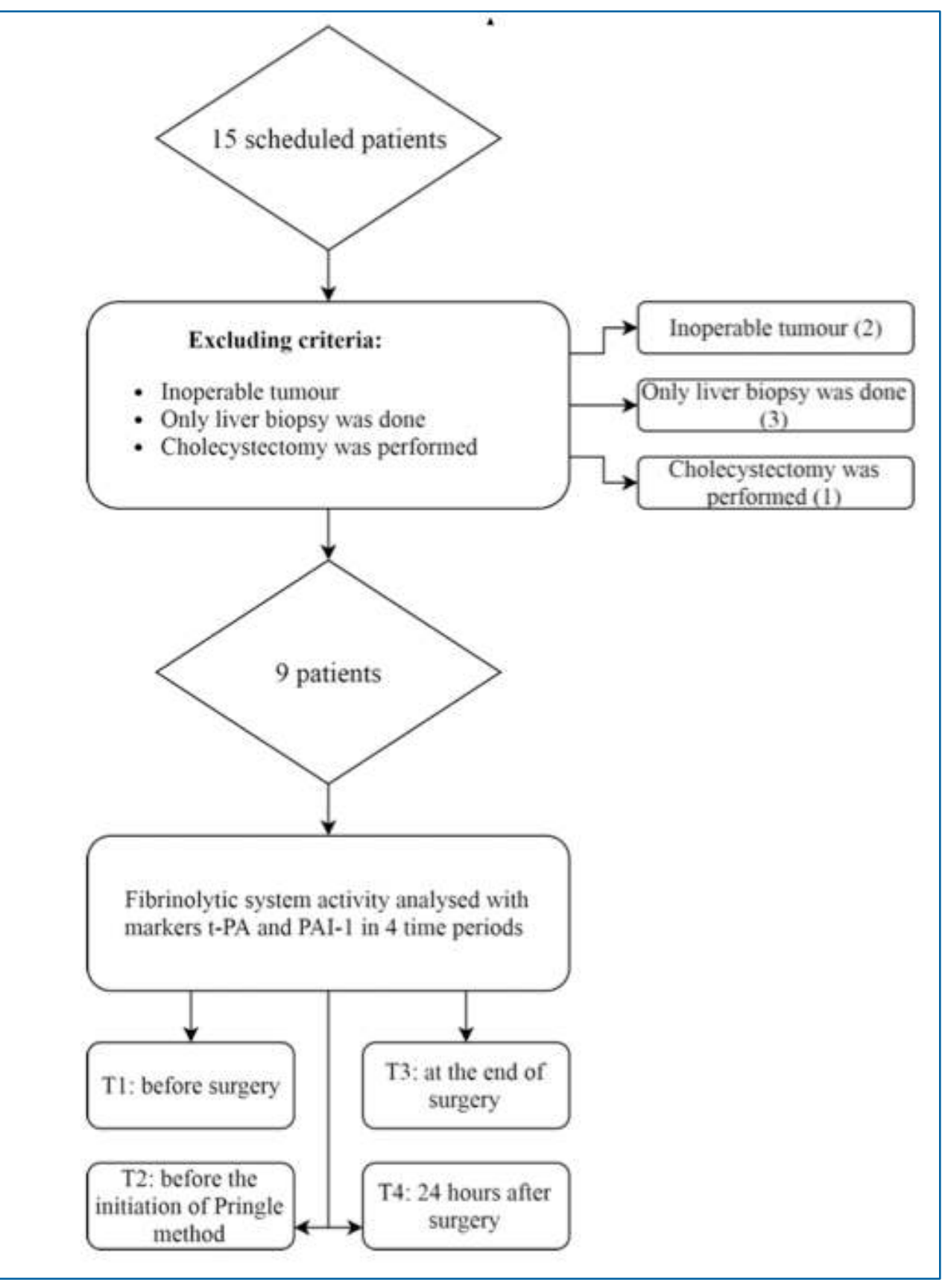

Figure 1 / Liver resection surgery patients eligibile for the study.
Results

After exclusion of six patients, who only underwent biopsies, we included six women and three men aged $49.1 \pm 19.6$ years.

PAl-1 plasma concentration $(n=9)$ rose from $6.25 \pm 2.25$ at T1 through 17.30 $\pm 14.59 \mathrm{ng} / \mathrm{ml}$ at $\mathrm{T} 2$ and $28.74 \pm 20.4(p=0.007)$ and $22.5 \pm 16.0 \mathrm{ng} / \mathrm{ml}(p=0.04)$ respectively, at $\mathrm{T} 3$ and $\mathrm{T} 4$.

t-PA plasma concentration $(n=9)$ increased from $4.76 \pm 3.08 \mathrm{ng} / \mathrm{ml}$ at T1 through $8.00 \pm 5.10 \mathrm{ng} / \mathrm{ml}(p=0.012)$ at T2 and decreased to $4.25 \pm 2.29 \mathrm{ng} /$ $\mathrm{ml}$ and $3.04 \pm 3.09$ at T3 and T4, respectively. Plasma t-PA level at T2 was significantly different from those at T1, T3 and T4 ( $p<0.004)$.

In patients subjected to the Pringle maneuver $(n=6)$, plasma t-PA levels increased from $4.36 \pm 2.68 \mathrm{ng} / \mathrm{ml}$ at T1 through $9.33 \pm 4.53 \mathrm{ng} / \mathrm{ml}$ at T2 $(p=0.001)$, and subsequently decreased to $3.78 \pm 2.30$ at T3 ( $p=0.011$ vs T2) and to $2.93 \pm 3.14 \mathrm{ng} / \mathrm{ml}(p=0.037 \mathrm{vs}$. T2) at T4

Mean blood loss was $1377.7 \pm 1062.8 \mathrm{ml}$. Seven patients received blood products. Patients with higher PAI-1 levels at T3 received more fresh frozen plasma $(r=0.79 ; p=0.01)$ and red blood cells $(r=0.88 ; p=0.002)$.

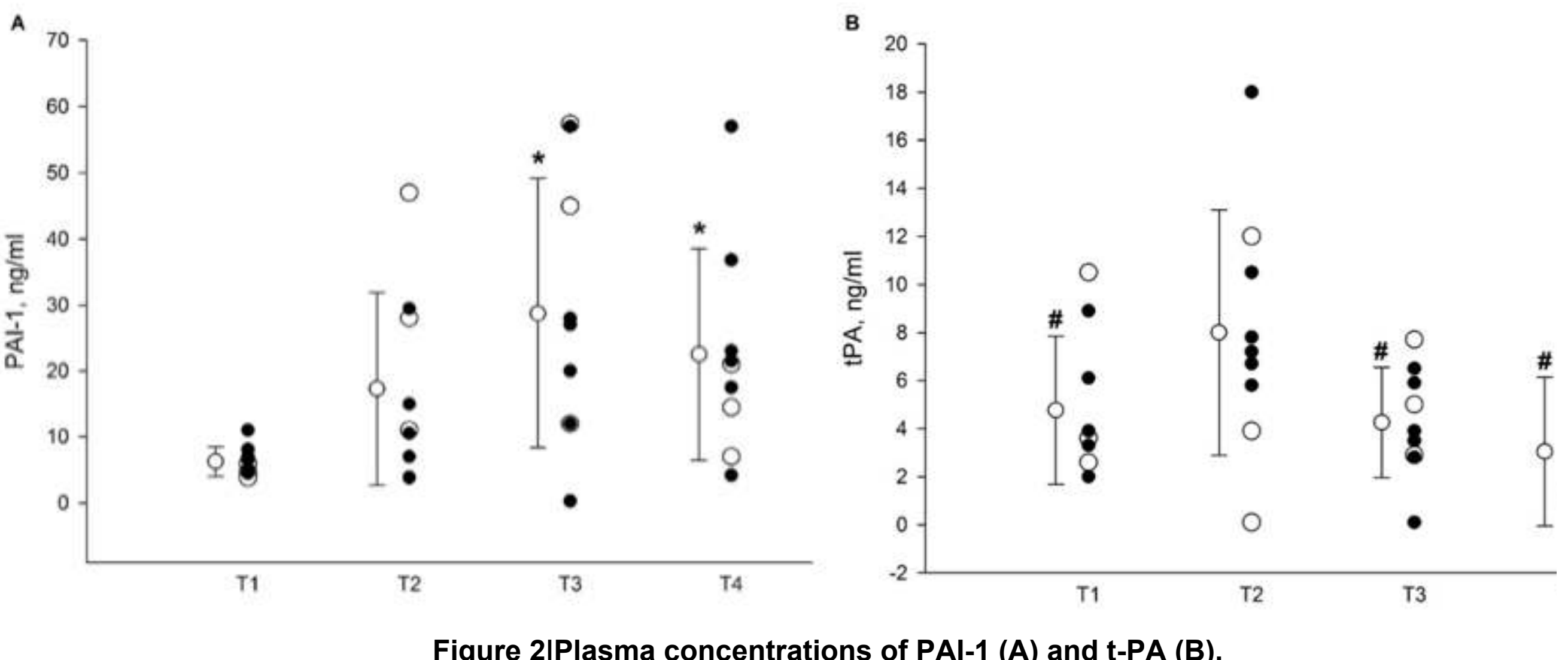

Closed circles represent patients subjected to the Pringle maneuver $(n=6)$; open circles - Pringle maneuver was not performed $(n=3)$. $(A)^{*}$ denotes $p<0.05$ vs T1; \# denotes $p<0,05$ vs. T2

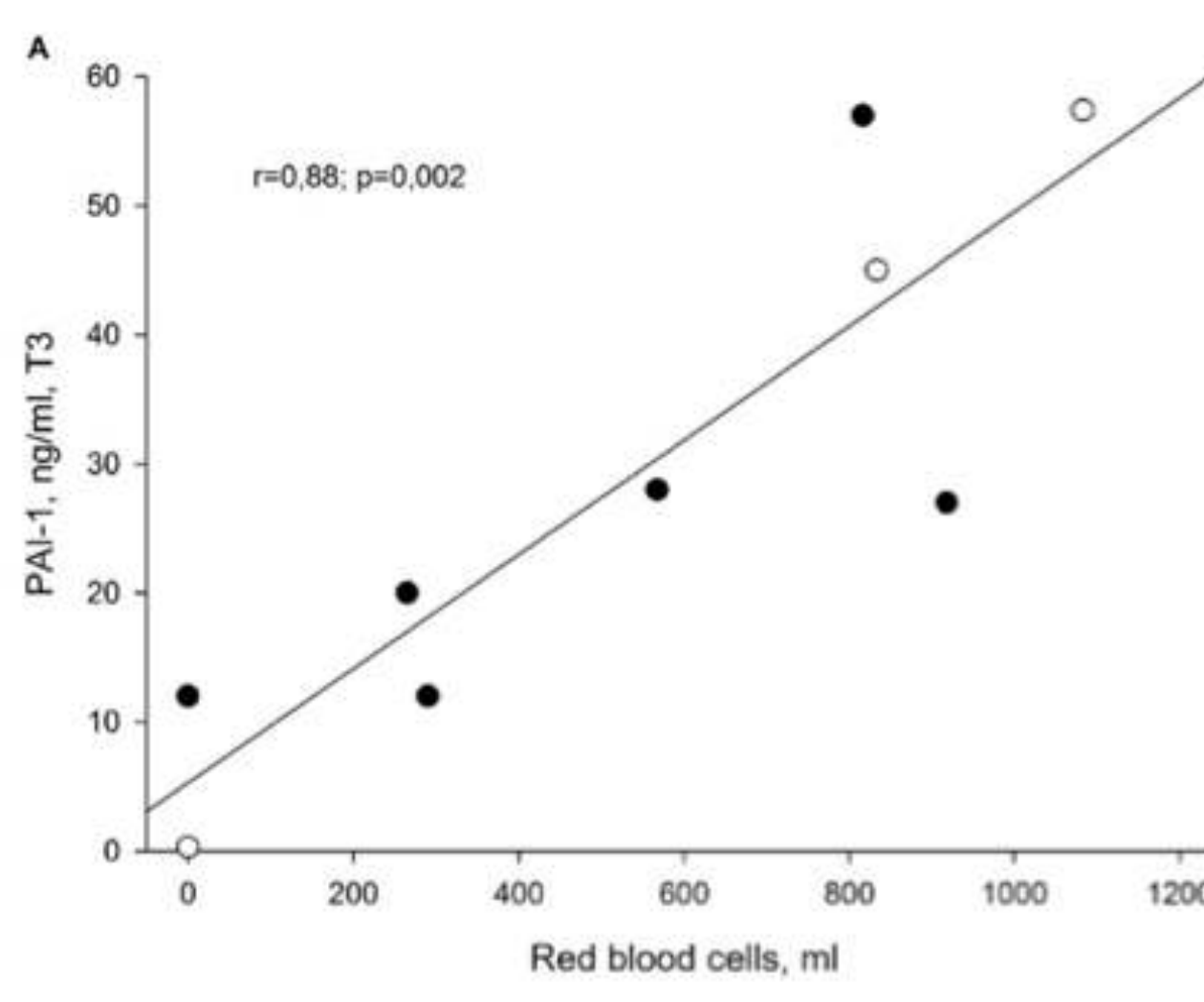

Figure 3| (A) Correlation between PAI-1 and transfused volume of red blood cells at the end of surgery (T3).
Conclusions During liver surgery, fibrinolysis increased, as evidenced by rises in plasma PAI-1and t-PA, especially after start of surgery and following the Pringle maneuver. Transfused volumes of blood products correlated with higher plasma concentrations of PAI-1. 